\title{
Digital image analysis to estimate the minimum number of Eurytrema coelomaticum eggs in the uterus of adult specimens
}

\author{
F. A. DA SILVA JÚNIOR ${ }^{1 *}$, C. MONTEIRO DA SILVA ${ }^{1}$, F. B. DE ALMEIDA², R. RODRIGUES-SILVA
}

${ }^{1}$ Faculdade de Ciências Biológicas e da Saúde - Universidade Federal dos Vales do Jequitinhonha e Mucuri (UFVJM). Rod. MGT 367, 5000 - Alto da Jacuba, Diamantina - MG, 39100-000, Brazil, "E-mail: fidelisjunior@hotmail.com, fidelisjunior@ufvim.edu.br, 2Laboratório de Helmintos Parasitos de Vertebrados - LHPV, Instituto Oswaldo Cruz - IOC, Fundação Oswaldo Cruz - FIOCRUZ, Avenida Brasil 4365, Manguinhos, Rio de Janeiro, RJ, 21040-360, Brazil, *E-mail: rosanrsilva@gmail.com, rsilva@ioc.fiocruz.br

\section{Article info}

Received November 15, 2017 Accepted March 12, 2018

\begin{abstract}
Summary
This study was carried out to estimate the minimal number of eggs present in adult $E$. coelomaticum uterus. Samples were collected during post-mortem inspection and were submitted to light microscopy (bright field). The length, width, the total area of the parasite, uterus, and eggs were measured. The ImageJ software was used to calculate the area of the different parameters analyzed in this study. It was possible to observe that the uterus corresponds on average to $51.9 \%$ of the total area of the parasite (ranging from 45 to $64 \%$ ). The number of eggs present in the uterus of parasites ranged from 5,946 to 15,813 . To estimate the number of eggs three scenarios were considered, where the first taken into account the number of whole eggs observed in the image. In the second way to estimate the number of eggs, all the structures were considered (whole eggs and fractions that could be delimited) and compared with manual counting. Finally, in the last scenario, was considered an occupancy rate of $100 \%$ of the uterine area per eggs, since there are overlapping eggs and these cannot be correctly delimited and accounted for. This study describes an important tool for quantifying eggs in a nondestructive manner and aggregate information until then is not explained by other works.
\end{abstract}

Keywords: Trematoda; Dicrocoeliidae; ImageJ

\section{Introduction}

The digenetic trematode Eurytrema coelomaticum (Giard \& Billet, 1892) Looss, 1907 is parasite of pancreatic ducts of ruminants and are endemic in several regions of the world, including countries of South America, Europe and Asia (Sakamoto et al., 1981; Ilha et al., 2005; Sakamoto \& Oikawa, 2007; Quevedo et al., 2013). In Brazil, this helminth is widely distributed and commonly found in slaughterhouses in several states (Azevedo et al., 2004; Bassani et al., 2006) The life cycle is heteroxenic, requiring two intermediate hosts and another definitive. The primary intermediate host is the mollusk Bradybaena similaris (Férussac, 1821) (Gastropoda, Xanthonychidae) (Illha et al., 2005). In Brazil, the second intermediate host is a grasshopper of the genus Conocephalus (Thunberg, 1815) (Orthoptera, Tettigoniidae) and in some regions of Asia the cricket belongs to the genus Oecanthus (Serville, 1831) (Orthoptera, Gryllidae) (Ilha et al., 2005; Pinto \& De Melo, 2013, 2016). Finally, the definitive hosts become infected upon ingestion of infected arthropods with metacercariae when feeding on grazing, thus completing the cycle (Bassani et al., 2007).

The eurytrematosis is clinically asymptomatic, but is a silent disease which causes losses in milk and meat production. When it considered in a little number of animals these losses are diluted and not clearly visible. But, when you consider a loss of $1 \mathrm{I}$ of milk or $1 \mathrm{~kg}$ of meat production per animal in a cattle with 10,000 animals this is very significant in an economic point of view. Although

\footnotetext{
* - corresponding authors
} 
it is commonly found infecting herds in Brazil, there are no calculations about the impact of these organisms on national livestock production, with estimated costs varying from 1 to $3 \%$ of the total amount (Illha et al., 2005). Is associated with hyperplasia and hypertrophy of the pancreas and bile ducts, as well as fibrosis and partial or total obliteration of the pancreatic ducts when in massive infections (Rachid et al., 2011; Figueira et al., 2014; Schwertz et al., 2016).

The World Association for the Advancement of Veterinary Parasitology (WAAVP) recommends performing count of eggs per gram of faeces (EPG) to assess the intensity of parasitic infection of various trematodes species (Wood et al., 1995). Observation of the EPG levels is largely recommended and is historically used as a diagnostic and monitoring tools in the control of parasites of veterinary importance, supporting in the treatment and mainly in prophylaxis (Bassani et al., 2007; Wood et al., 1995). Although it is an important tool for the evaluation of worm eggs, in general, the technique presents values underestimated and can in some cases compromise the treatment and the prophylaxis, fact that reinforces the importance of the present study. Gassó et al. (2015) have shown that depending on the location where the parasite is situated the eggs prevalence has decreased due to the routes through which the eggs must pass until reaching the intestine. They further cite that accuracy has declined over time and therefore it is recommended that samples be processed within 5 days after collection. The E. coelomaticum eggs are oval with a coloration ranging from yellowish to brownish when immature and brown when fertile (Rachid et al., 2011; Pinheiro et al., 2015). Egg size ranges from 39 to $50 \mu \mathrm{m}$ in length by 20 to $32 \mu \mathrm{m}$ in width (Yamamura, 1989; Mohanta et al., 2015; Pinheiro et al., 2015).

Yamamura (1989) analyzing the oviposture of E. coelomaticum (in vitro) observed an average daily of 641 eggs. Brandolini and Amato (2001) testing different physiological media observed that Locke solution presented the best oviposture rate with an average of 746 \pm 139 eggs, followed by Earle solution with $304.6 \pm 154.7$ and finally the saline solution to $0.85 \%$ with $194.5 \pm 132$ eggs. About this information, there are no records in the literature of estimate number of eggs present in the uterus of E. coelomaticum.

The use of techniques such as the analysis of digital images makes possible the estimation of eggs present in an adult animal and thus aggregates information about its fecundity and epidemiology (Rosati et al., 2015; Mains et al., 2008). In this work, we describe methodologies that were used to calculate the mean uterine size, the proportion of the organ in relation to the total size of the animal, as well as to estimate the number of eggs of $E$. coelomaticum according to the occupancy rate of the parasite uterus.

\section{Materials and Methods}

Samples of $E$. coelomaticum were obtained during the post-mortem inspection at the slaughterhouse in the city of Campo Belo, Minas Gerais, Brazil. The samples were processed at the Labo-
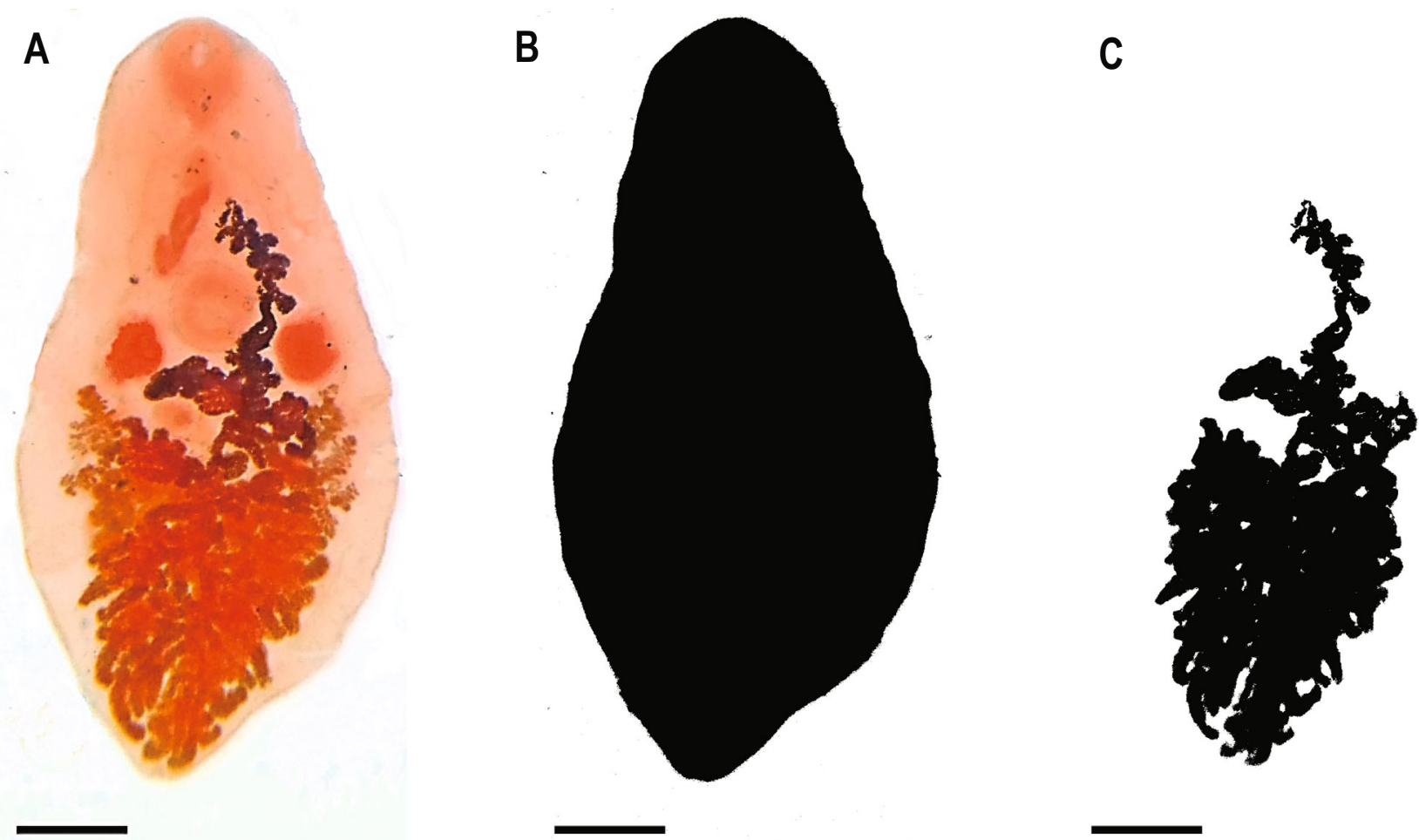

Fig. 1. The binarization process to measure the surface area. (A) general view from Eurytrema coelomaticum. (B) binary image after transformation in Image software showing the total area of the parasite. (C) uterus area after the binarization process. Scale bar $1 \mathrm{~mm}$ 


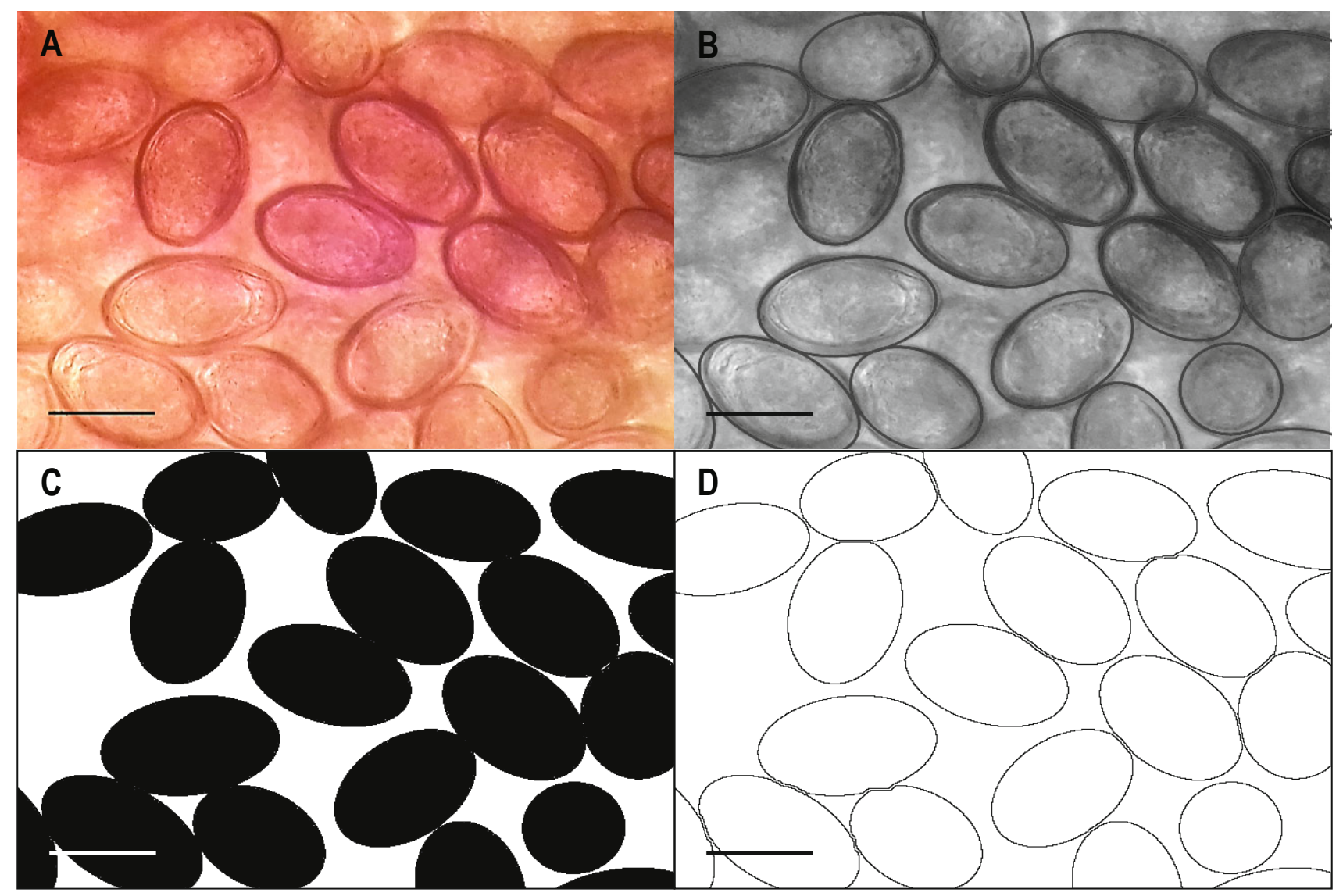

Fig. 2. Automatic counting process of Eurytrema coelomaticum eggs. (A) Original image. A micrograph (bright field) of the surface of E. coelomaticum eggs.

(B) recognition pattern for structures by ImageJ software. It is the first step to the binarization process. (C) a secondary binary image is created. (D) transformation of the binary image to segmented lines with the capacity to measure the total area and perimeter of eggs. Scale bar $30 \mu \mathrm{m}$.

ratory of Parasitic Diseases in Department of Veterinary Medicine of Universidade Federal de Lavras (DMV-UFLA), Lavras, Minas Gerais, Brazil.

The pancreas were washed inside of a bowl, so that, E. coelomaticum specimens could be recovered after the passage of water retained in the bowl through nylon sieves with a mesh of 150 $\mu \mathrm{m}$. Subsequently, transverse and longitudinal sections were performed in the bovine pancreas in order to investigate the presence or absence of the parasites. For the light microscopy analysis the specimens were washed in $0.9 \%$ physiological solution and fixed in AFA (Glacial Acetic Acid Solution, 2 parts, 37 \% Formalin, 5 parts and $70 \%$ Ethanol, 93 parts) (Corrêa et al., 2016). After fixation were placed between two glass slides and were lightly pressed for maintenance of their original shape. They were then stained with alcoholic chlorhydric carmine and observed under a light microscope (Olympus CX22 Led), coupled with a camera Moticam 5.0 MP and using Images Plus 2.0 software (Motic China Group Co LTD). All images used for comparison were photographed at the same magnification and with the same resolution (amount of pixels in the images)

To measure the total area of the adult animal, uterus and eggs,
ImageJ software (NIH, USA) was used. In order to separate the uterus from the animal in the images was used a tool of creation of vectors in the Gimp 2.8 software (GNU Image Manipulation Program Open Source), and in this way it was possible to calculate the size of the organ through of creation of a secondary image with the same amounts of pixels of the original image. In ImageJ program, all images captured through the microscope and measured with the Images Plus 2.0 software were converted to gray scale images. Subsequently, the threshold function was used to improve the contrast of the structures to be analyzed in relation to the background. After the use of the threshold function, if there was any residual "noise" in the image (material that was not being evaluated), it was removed using the Gimp 2.8 software. For the delimitation between one object and another, the watershed tool was used. The total area of parasite, uterus and eggs was measured using the tools: Measure or Analyze Particles. The process of binarization, measurement and counting of the items evaluated in this work can be visualized in Figs. 1, 2 and 3 .

From these data it was possible to estimate the total parasite area, uterine size and number of eggs per $\mathrm{mm}^{2}$, adapting the methodology used by Rosati (2015). In order to verify the minimal number 


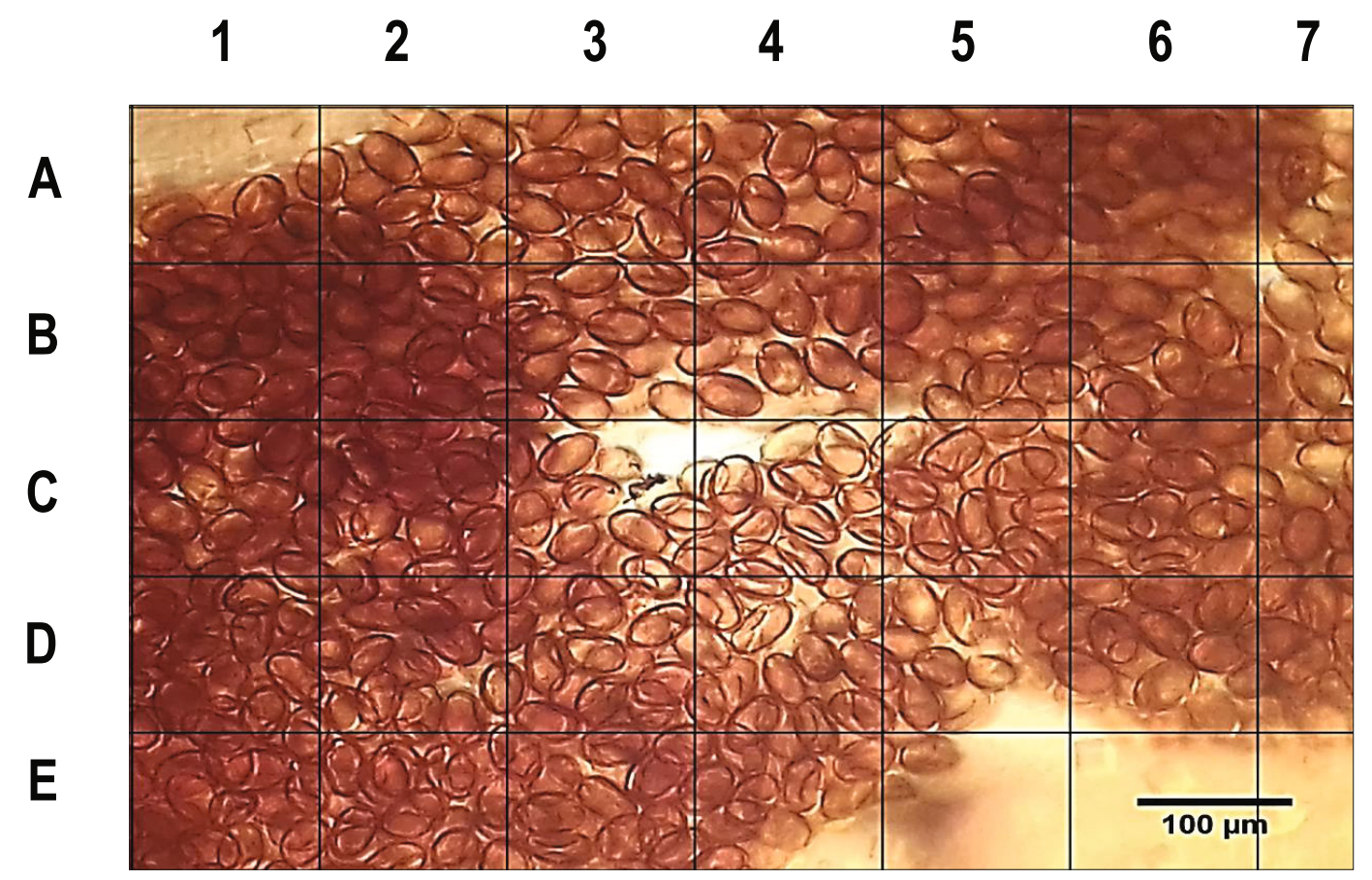

Fig. 3. Manual counting process: represent a picture with grids where was counted the Eurytrema coelomaticum eggs.

of eggs of $E$. coelomaticum, three scenarios were considered. In the first scenario, only the whole eggs observed in the field were counted. In the second process to estimate the number of eggs, were considered the areas of all visible structures and with clear delimitation. Manual count of eggs was also performed so that to establish the accuracy of the software. The comparison between the counting performed by the software and manually was performed only in this scenario because they are measures that have the closest characteristics and could be correlated. Finally, in the last scenario, it was considered an occupation of $100 \%$ of the eggs in the image, since that the eggs into the uterus has three-dimensional characteristics, there are overlapping eggs and therefore cannot be correctly visualized and delimited in the image, which has a character two-dimensional. In this way it was calculated the maximum amount of eggs that can be seen in an image with $230 \mathrm{x}$ $170 \mu \mathrm{m}$, taking as reference the average area of the eggs.

To measure the mean area of adult individuals, their respective uterus and the average egg size, an arithmetic mean was calculated based on 10 images. The manual counts were performed on images with the same area (in micrometers) and the values were extrapolated to $\mathrm{mm}^{2}$, using a cross multiplication. The area used for counting the eggs by Image J software was $230 \times 170 \mu \mathrm{m}$ (totaling $0.0391 \mathrm{~mm}^{2}$ ) and the images used for manual counting had an area of $790 \times 593 \mu \mathrm{m}$ (equal to $0,468 \mathrm{~mm}^{2}$ ). To facilitate the manual counting of eggs, the selected images were divided into grids and these were numbered from 1 to 7 in the columns and from "A" to " $E$ " in the lines according to Fig. 3.

\section{Statistical Analysis}

The paired T-test was applied to compare the number of eggs observed through manual counting and software. Linear regressions were made between the uterus area and total body area, and between the number of eggs observed by manual and software counts. The significance level of $5 \%$ was used for both cases.

\section{Ethical Approval and/or Informed Consent}

All applicable national and institutional guidelines for the care and use of animals were followed. The study entailed samples of the normal meat inspection process of animals sent to slaughter for human consumption. This study was performed in strict accordance with the recommendations of the brazilian law $n^{0} 11.794 / 08$ (which regulates procedures for the scientific use of animals) and Normative Resolutions of CONCEA (National Council for Control of Animal Experimentation).

\section{Results}

The adult specimens showed a flat body, fusiform or oval shape with an average length of $7.67 \mathrm{~mm}( \pm 0.34)$ and $3.66( \pm 0.41)$ of width. The average area of adult individuals corresponded to 29.4 $\pm 4.26 \mathrm{~mm}^{2}$, while the average area of the uterus represented 15.5 $\pm 3.18 \mathrm{~mm}^{2}$. The total area of $E$. coelomaticum varied between 21 and $36 \mathrm{~mm}^{2}$ and the total area of the organ oscillated between 9.5 and $20.6 \mathrm{~mm}^{2}$. The eggs showed average values of area equal $980 \mu \mathrm{m}^{2}$ and average perimeter it was of $119 \mu \mathrm{m}(\mathrm{n}=200)$. The 
Table 1. Registered values for the total area of Eurytrema. coelomaticum, uterus size, proportional percent of the organ in relation to total area of parasite and eggs occupational rate into uterus lumen.

\begin{tabular}{|c|c|c|c|c|}
\hline \multirow[t]{2}{*}{ Sample } & \multicolumn{2}{|c|}{ Total area $\left(\mathrm{mm}^{2}\right)$} & \multirow{2}{*}{$\begin{array}{c}\text { Uterus/Animal } \\
(\%)\end{array}$} & \multirow{2}{*}{$\begin{array}{c}\text { Occupancy rate } \\
(\%)\end{array}$} \\
\hline & E. coelomaticum & Uterus $\left(\mathrm{mm}^{2}\right)$ & & \\
\hline 1 & 27.3 & 14.3 & 51.98 & 85 \\
\hline 2 & 29.2 & 14.2 & 47.98 & 55.6 \\
\hline 3 & 30.8 & 16.9 & 55.00 & 57 \\
\hline 4 & 36 & 18.3 & 50.00 & 63 \\
\hline 5 & 21 & 9.5 & 45.00 & 55.4 \\
\hline 6 & 28.4 & 18.2 & 63.98 & 65.75 \\
\hline 7 & 32.2 & 14.5 & 45.00 & 66.14 \\
\hline 8 & 28 & 15.4 & 55.00 & 55.4 \\
\hline 9 & 26.8 & 12.7 & 45.00 & 55 \\
\hline 10 & 34.4 & 20.6 & 60.00 & 55.6 \\
\hline Average & 29.4 & 15.5 & 51.9 & 61.38 \\
\hline Standard deviation & 4.26 & 3.18 & 6.60 & 9.43 \\
\hline Minimum value & 21 & 9.5 & 45.0 & 55 \\
\hline Maximum value & 36 & 20.6 & 64.0 & 85 \\
\hline
\end{tabular}

recorded values corresponding to the animals, uterus, proportion that organ represents in relation to the total size of the parasite and the percentage of occupation of the eggs in the lumen of the uterus are presented in Table 1.

The linear regression equation for the size of the uterus according to the total area of the animal $\left(\mathrm{mm}^{2}\right)$ calculated was $y=0.6196 \mathrm{x}$ -2.7614 and $R^{2}=0.6875$ which was significant $(p<0.05)$. The prediction of the size of the uterus according to the body area of the parasite can be seen in Fig. 4 .
In the first scenario, an average of 15 whole eggs was recorded (raging from 10 to 29 eggs per image). Considering only the average eggs seen in the images (15 eggs in $0.0391 \mathrm{~mm}^{2}$ ) and using a cross multiplication, the estimated number of eggs was equal 383.63 per $\mathrm{mm}^{2}$. Using the estimation of whole eggs visible per $\mathrm{mm}^{2}$ and considering the average area of the uterus of $E$. coelomaticum, it was estimated that an adult specimen has around 5,946 eggs in its uterus.

In second scenario, the average area occupied by eggs in lumen

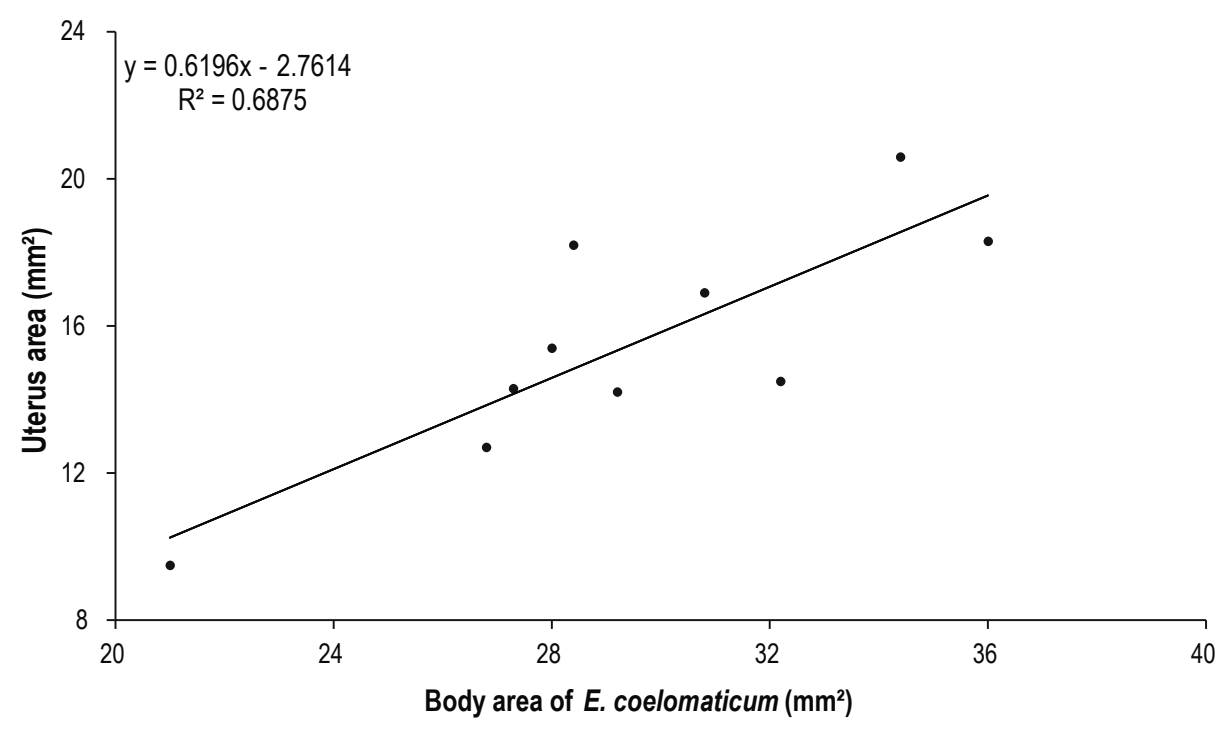

Fig. 4. Correlation between Eurytrema coelomaticum total area $\left(\mathrm{mm}^{2}\right)$ and uterus size. Linear regressions equations were determined: $y=0,6196 x-2,7614$ where $y$ is estimated size of the organ and $x$ is the body size (total area). $R^{2}=0,6875, p<0,05$. The $X$ axis it was changed, initializing in 20 . 


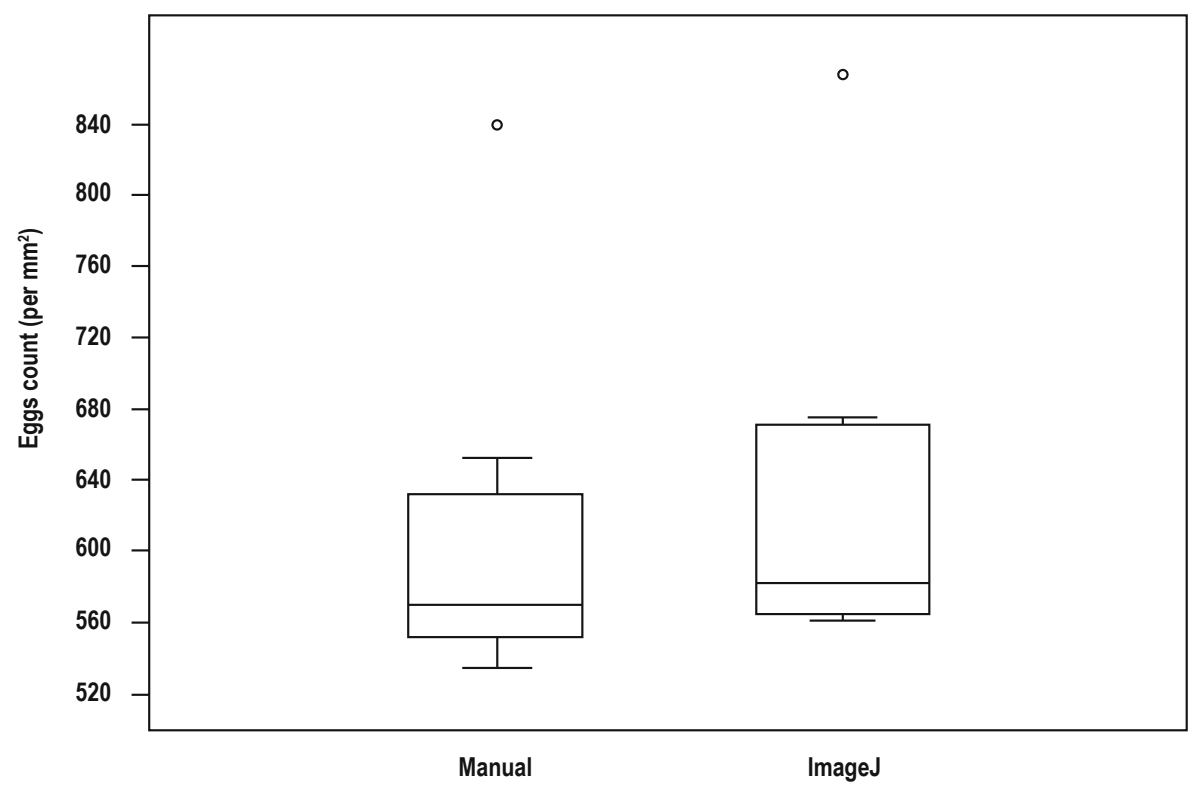

Fig. 5. Box plot of Eurytrema coelomaticum eggs per area $\left(\mathrm{mm}^{2}\right)$ counted manually and automatized way. No significant difference were observed between counts with $p$ value $>0.05$.

of uterus was considered, i.e, whole eggs and portions that could be delimited and that corresponding to eggs. The area in image filled with eggs represented an average of $0.024 \mathrm{~mm}^{2}$. The average percentage of the area occupied by eggs in the lumen of the uterus was $61.38 \%$ (ranging from $55 \%$ to $85 \%$ ). Multiplying the average percentage of eggs occupancy in the uterine lumen by the average area of the organ $\left(15.5 \mathrm{~mm}^{2}\right)$ and dividing the result by 100 , reached the number of $9.51 \mathrm{~mm}^{2}$ (corresponding to the area really used by eggs). Considering that an egg has an average area of $980 \mu \mathrm{m}^{2}$, in order to obtain the second estimate it was divided the area of occupation of the eggs $\left(9.51 \mathrm{~mm}^{2}\right)$ by average area of an egg, resulting at the estimated number of 9,704 eggs. Dividing the estimated number of eggs by the average area of the organ $\left(15.5 \mathrm{~mm}^{2}\right)$ reached the value of 626 eggs per $\mathrm{mm}^{2}$. The mean number of eggs counted manually was 9,366, with 604 eggs per $\mathrm{mm}^{2}$ in the average. The distributions of the number of eggs and the respective outliers can be observed in Fig. 5.

In the T-test there was no significant difference considering an

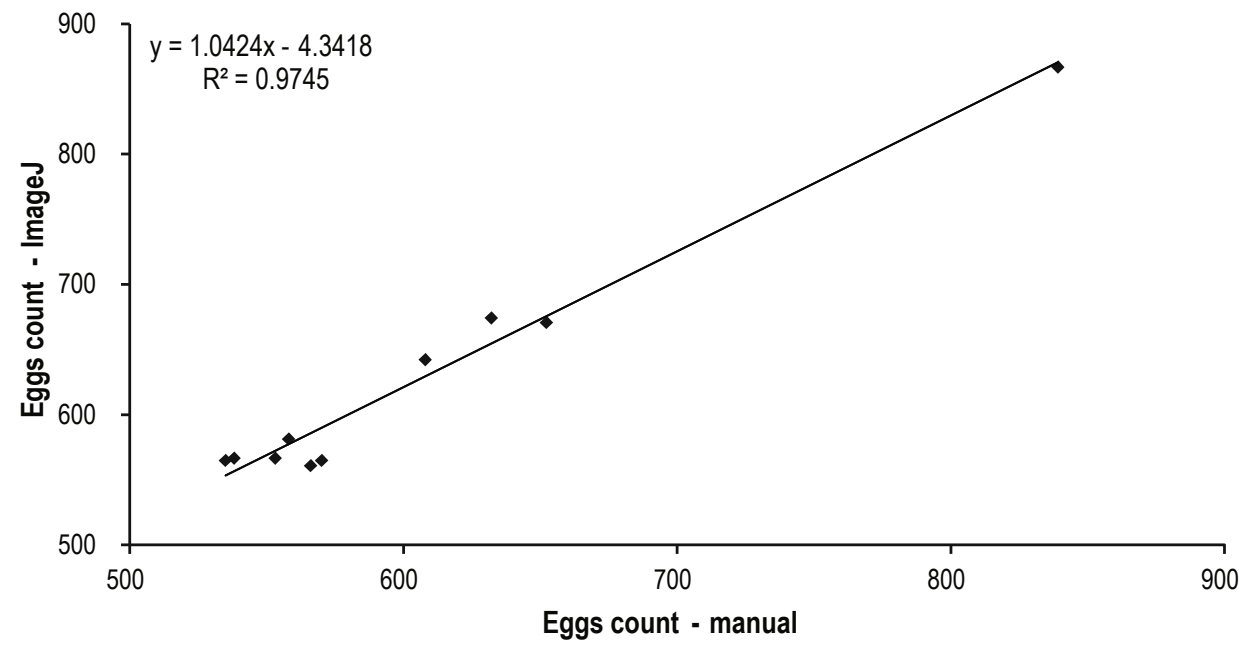

Fig. 6. Estimated amount of Eurytrema coelomaticum eggs in the parasite uterus, from cattle slaughtered in southern Minas Gerais, Brazil. Correlation between the number of eggs counted manually and through ImageJ software. Linear regression $y=1.0424 x-4.3418$, where $y$ is the predicted number of eggs estimated by the software and $x$ the variable manual count; $R^{2}=0.9745, p<0.05$. The $X$ and $Y$ axes it was changed, initializing in 500 . 


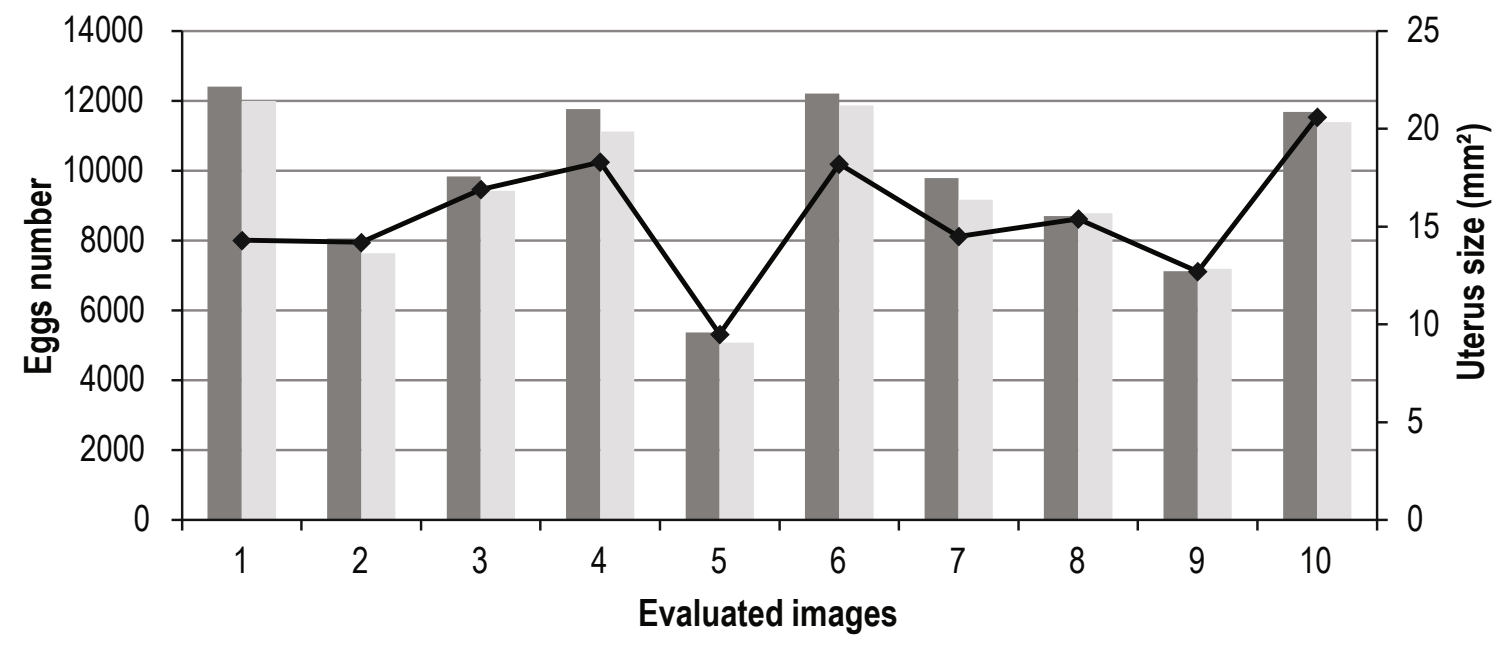

ImageJ software eggs count Manual eggs count $\neg$ Uterus

Fig. 7. Comparison of the number of manually counted eggs and the number of Eurytrema coelomaticum eggs registered by Image J software according to the area occupied by the eggs in lumen of the uterus and according to the size of the organ in square millimeters.

equivalent distribution for the variances of eggs numbers counted manually and estimated by the Image J software, with $p>0.05(p=$ 0.756). A linear regression with a prediction interval of $95 \%$ was performed for the number of eggs counted manually and automatic way, as can be seen in Fig. 6, with $R^{2}=0.9745$ and $y=1.0424 x-$ 4.3418. The variation in the number of eggs is directly related to the size of the uterus as well as the occupancy rate in lumen by the eggs, as can be observed in Fig. 7.

Finally, in the third scenario, an occupancy rate of $100 \%$ of the image per eggs was considered. Therefore, it was estimated that in $0.0391 \mathrm{~mm}^{2}$ exist 39.89 eggs $\left(0.0391 \mathrm{~mm}^{2} \div 980 \mu \mathrm{m}^{2}\right)$ and consequently we reached the value of $1,020.20$ eggs per $\mathrm{mm}^{2}$. So, if consider the average size of the uterus of an adult animal it possible concludes that have the number estimate of 15,813 . eggs in a $E$. coelomaticum specimen. A linear regression was performed and an equation was defined to estimate the number of eggs present in adults according to the area of the uterus. The equation for calculating the number of eggs considering an occupancy rate of $100 \%$ of the uterus is: $y=1020,4 x+1,82^{-12}$, where $y$ is the predicted number of eggs and $x$ the variable size of uterus in $\mathrm{mm}^{2} ; \mathrm{R}^{2}=1, \mathrm{p}$ value $<0.05$ )

\section{Discussion}

According to Neuhaus (1978), the length of the uterus of some trematodes correlates with the size of the body. In the present study, it was observed that there is a relation between the size of the animal and the size of the uterus with $p$-value $<0.05$. The positive and significant relationship between the body size and uterus indicates that the addition of one is accompanied by proportional increase of another, without, however, requiring dependence between them, but allowing that from the first one can be estimated the value of the second.

The E. coelomaticum uterus has eggs clusters in its lumen, and there is no effective method to quantify the total number of eggs inside the organ without using methods that destroy internal structures of the parasite, causing losses of materials throughout the process of incision and removal of organ, affecting the count and later the results. ImageJ software provides precise measurements of surface area and is, therefore, an exceptional tool to support in counting and consequently creating estimates closer to reality. Mains et al. (2008) used successfully a digital image analysis supported with ImageJ program to estimate the number of aedine mosquitoes eggs using similar methodologies applied in this work. In the present study, a simple linear correlation was performed to evaluate the expected size of the uterus of adult animals using the total area of $E$. coelomaticum like parameter to calculate. This procedure was performed since the masses of the specimens were not verified, nor of organs in question, difficulting to estimate by means of an exponential logarithmic equation through of static allometric development. Valero et al. (2005) used as reference to evaluate the development of the uterus of Fasciola hepatica obtained in cattle from Bolivia, Spain and France an allometric growth model, where the curve shows an exponential growth. Neuhaus (1978) used to calculate the equation of the uterus length of Dicrocoelium dendriticum, Pleurogenoides medians and Fasciola hepatica the corrected body size that is equal to $\sqrt{\text { width }} \times$ length . The author observed a sigmoid curve with the middle part presenting a linear section, that he considered an allometric growth.

In the literature, there is no description of estimates of total num- 
ber of eggs present in the uterus of $E$. coelomaticum. There are studies that evaluated the oviposture rate of the parasite in vitro, and these studies observed a deposition ranging from 194 to 746 eggs per day in different physiological solutions (Yamamura, 1989; Brandolini \& Amato, 2001). According to Bassani et al. (2007) the proportion of eggs eliminated and observed via EPG is not directly related to number of parasites in the host, even considering those who lay their eggs directly in lumen of intestine.

Our results indicate that simple linear regressions can be established to calculate the burden of eggs based in uterine size, and the equations can be defined by considering the occupancy rate in lumen of uterus or by considering a percentage of $100 \%$. Rosati et al. (2015), used a different design to estimate the number of eggs of blow flies, since they had masses of eggs (aggregates) and, therefore, it was possible to determine the depth of these agglomerates and thus to calculate the volume present in the analyzed samples by created a three-dimensional model to estimate the number of eggs through volume and not only the surface area. Despite the relative success with regard to egg estimation, it is important to note that the methodology adopted in this work has limitations such as the fact that the images analyzed by the software have two-dimensional characteristics, whereas the parasites have three-dimensional conformation. In this way the total number of eggs ends up being underestimated, being calculated in a certain way the minimum number of eggs that can be visualized, since those eggs that are not captured by the image end up not going into calculation of estimate. Therefore, considering the three scenarios established in the present work, it is evident that the minimum numbers of eggs present in $E$. coelomaticum uterus ranges from 5,946 . to 15,813 , and that is necessary to develop a methodology for extraction of the organ without loss of material and thus accurately determine the total number of eggs present.

\section{Conclusions}

The procedure performed in this study have some advantages like the fact that free software are used (ImageJ and Gimp), and these do not require expensive or specialized hardware. Another positive aspect related to technique is that the scanned images provide permanent records that can be checked by manual counting if this is desired.

Using the technique described in this work it is possible to estimate thousands of eggs in a short time and with a great accuracy. The time required for manual counting can be a complication in experiments that require egg counting, demanding a substantial effort, loss of time and resources. Therefore the method described in this work includes a substantial reduction of time, greater consistency in the obtained data, and decrease of errors besides taking the human bias. This study describes an important tool to quantify the number of eggs in a non-destructive way and aggregates information not explained previously by others works.

\section{Conflict of Interest}

The authors declare that there are no conflicts of interest regarding the publication of this article.

\section{References}

Azevedo, J.R.D., Mannigel, R.C., Agulhon, A.Z., Thiago, R., BarBIÉRI, A.W., Oliveira, D.C.L.D., Headley, S.A. (2004): Prevalence and geographical distribution of bovine prevalence eurytrematosis in cattle slaughtered in northern Paraná, Brazil. Pesqui. Vet. Bras., 24(1): 23-26

Bassani, C.A., Sangioni, L.A., Paulo, J., Saut, E., Headley, S.A., YamamuRA, M.H. (2007): Euritrematose bovina. [Bovine eurytrematosis]. Ciencias Agrar. Londrina, 28(2): 299-316 (In Portuguese)

Bassani, C.A., Sangioni, L.A,, Saut, J.P.E., Yamamura, M.H., HeadLEY, S.A. (2006): Epidemiology of eurytrematosis (Eurytrema spp. Trematoda: Dicrocoeliidae) in slaughtered beef cattle from the central-west region of the State of Paraná, Brazil. Vet. Parasitol., 141(3-4): 356-361. DOI: 10.1016/j.vetpar.2006.06.003

BRANDolinI, S.V.P.B., Amato, S.B. (2001): Desenvolvimento de Eurytrema coelomaticum (Giard \& Billet) (Digenea, Dicrocoeliidae) em Bradybaena similaris (Férussac) (Gastropoda, Xanthonychidae). [Development of Eurytrema coelomaticum (Giard \& Billet) (Digenea, Dicrocoeliidae) in Bradybaena similaris (Férussac) (Gastropoda, Xanthonychidae)]. Rev. Bras. Zool., 18(2): 499-510. DOI: 10.1590/S0101-81752001000200021 (In Portuguese)

Figueira, G.F., Oliveira, V.H.Sd., Taroda, A., Alfieri, A.A., HeadLEY, S.A. (2014): Molecular characterization of Eurytrema coelomaticum in cattle from Paraná, Brazil. Brazilian J. Vet. Parasitol., 2961(3): 383-386. DOI: 10.1590/S1984-29612014022

ILHA, M.R.S., LORETTI, A.P., ReIS, A.C.F. (2005): Wasting and mortality in beef cattle parasitized by Eurytrema coelomaticum in the State of Paraná, southern Brazil. Vet. Parasitol., 133(1): 49-60. DOI: 10.1016/j.vetpar.2005.02.013

MaIns, J.W., Mercer, D.R., Dobson, S.L. (2008): Digital image analysis to estimate numbers of Aedes eggs oviposited in containers. J. Am. Mosq. Control Assoc., 24(4): 496-501. DOI: 10.2987/5740.1 Mohanta, U.K., IchiKaWA-SeKI, M., HayashI, K., ItagaKI, T. (2015): Morphological and molecular characterization of Eurytrema cladorchis parasitizing cattle (Bos indicus) in Bangladesh. Parasitol. Res., 114(6): 2099-2105. DOI: 10.1007/s00436-015-4398-y NeuHaus, W. (1978): Die Metrik des Uteruswachstums bei digenen Trematoden. [The Metric of uterine growth in digenetic's trematodes]. Zeitschrift für Parasitenkd., 55(3): 209-221. DOI: 10.1007/ BF00390372 (In German)

Pinheiro, J., Franco-Acuña, D.O., Oliveira-Menezes, A., Brandolini, S.V.P.B., Adnet, F.A.O., Lopes Torres, E.J., Miranda, F.J.B., SouZA, W., DamatTA, R.A. (2015): Additional study of the morphology of eggs and miracidia of Eurytrema coelomaticum (Trematoda). Helminthologia, 52(3): 244-251. DOI: 10.1515/helmin-2015-0039 Pinto, H.A., Melo, A.L. (2013): A checklist of cercariae (Tremato- 
da: Digenea) in molluscs from Brazil. Zootaxa, 3666(4): 449-475. DOI: 10.11646/zootaxa.3666.4.3

Pinto, H.A., Melo, A.L. (2016): Comments on human eurytremiasis in Brazil. World J. Exp. Med., 6(2): 55-58. DOI: 10.5493/wjem. v6.i2.55

Quevedo, P.S., Mendes, M., Felipe, G.P., Soares, M.P., Muller, G., FARIAS, N.A.R.F. (2013): Pancreatite intersticial crônica em bovino causada por Eurytrema coelomaticum. [Chronic interstitial pancreatitis in cattle caused by Eurytrema coelomaticum]. Ciência Rural. St. Maria, 43(8):1449-1452. DOI: 10.1590/S010384782013005000104 (In Portuguese)

Rachid, M.A., Aquino Neto, H.M., Facury-Filho, E.J., Carvalho, A.U., Valle, G.R., Vasconcelos, A.C. (2011): Chronic interstitial pancreatitis and chronic wasting disease caused by Eurytrema coelomaticum in Nelore cow. Arq. Bras. Med. Veterinária e Zootec., 63(3): 741-743. DOI: 10.1590/S0102-09352011000300028

Rosati, J.Y., Pacheco, V.A., Vankosky, M.A., Vanlaerhoven, S.L. (2015): Estimating the number of eggs in Blow Fly (Diptera: Calliphoridae) egg masses using photographic analysis. J. Med. Entomol., 52(4): 658-662. DOI: 10.1093/jme/tjv053

Sakamoto, T., Kono, I., Yasuda, N., Mohri, S., Honda, S., Yamauchi, C. (1981): Studies on Eurytrema coelomaticum : III. Development of Eurytrema coelomaticum in Mice. Mem. Fac. Agric. Kagoshima Univ., 17: 193-199

SAKAMOTO, T., OIKAWA, T. (2007): Cubic crystal protein inclusions in the neodermis of the pancreatic fluke, Eurytrema pancreaticum, and Eurytrema coelomaticum. Parasitol. Res., 101(5): 1393-1399. DOI: 10.1007/s00436-007-0658-9

Schwertz, C.I., Gabriel, M.E., Henker, L.C., Bottari, N.B., Carmo, Gd., Guarda, Nd.S., Moresco, R.N., Machado, G., Morsch, V.M., Schetinger, M.R.C., Stedille, F.A., Baska, P., Mattei, V., da SilVA, A.S., Mendes, R.E. (2016): Oxidative stress associated with pathological changes in the pancreas of cattle naturally infected by Eurytrema coelomaticum. Vet. Parasitol., 223: 102-110. DOI: 10.1016/j.vetpar.2016.04.034

Valero, M.A., Panova, M., Mas-Coma, S. (2005): Phenotypic analysis of adults and eggs of Fasciola hepatica by computer image analysis system. J. Helminthol., 79(3): 217-225. DOI: 10.1079/ $\mathrm{JOH} 2005301$

Wood, I.B., Amaral, N.K., Bairden, K., Duncan, J.L., Kassal, T., Malone, J.B., Pankavich, J.A., Reinecke, R.K., Slocombe, O., Taylor, S.M., VerCRUYSSE, J. (1995): World Association for the Advancement of Veterinary Parasitology (W.A.A.V.P.) Second Edition of Guidelines for Evaluating the Efficacy of Anthelmintics in Ruminants (Bovine, Ovine, Caprine). Vet. Parasitol., 58(3): 181-213. DOI: 10.1016/0304-4017(95)00806-2

YamamuRA, M.H. (1989): Algumas avaliações sobre a patologia e controle da euritrematíase bovina. [Some evaluations on the pathology and control of bovine euritrematosis] Rio de Janeiro: Universidade Federal Rural do Rio de Janeiro. Rio de Janeiro (In Portuguese) 